\title{
Activation of peroxisome proliferator-activated receptor- $\gamma$ induces apoptosis on acute promyelocytic leukemia cells via downregulation of XIAP
}

\author{
JIA-JUN LIU ${ }^{1 *}$, YUN-WEI GUO ${ }^{2}$, ZHI-GANG FANG ${ }^{1 *}$, XIAO-NING SI ${ }^{3 *}$, XIANG-YUAN WU ${ }^{4}$, \\ PEI-QING LIU ${ }^{5}$, DONG-JUN LIN ${ }^{1}$, RUO-ZHI XIAO ${ }^{1}$, YAN XU $^{1}$, CHUN-ZHI WANG ${ }^{1}$, \\ XU-DONG LI ${ }^{1}$, YI HE ${ }^{1}$ and REN-WEI HUANG
}

\begin{abstract}
Departments of ${ }^{1}$ Hematology; ${ }^{2}$ Gastrointestinal and Oncological Department; ${ }^{3}$ Hyperbaric Oxygen; ${ }^{4}$ Oncology, The Third Hospital of Sun Yat-Sen University, Guangzhou 510630; ${ }^{5}$ Laboratory of Pharmacology and Toxicology, School of Pharmaceutical Science of Sun Yat-Sen University, Guangzhou 510080, P.R. China
\end{abstract}

Received March 4, 2009; Accepted April 4, 2009

DOI: 10.3892/ijmm_00000273

\begin{abstract}
In the present study we investigated the in vitro apoptosis inducing effects of peroxisome proliferator-activated receptor- $\gamma$ (PPAR- $\gamma$ ) ligand ciglitazone (CGZ) on acute promyelocytic leukemia (APL) NB4 cells and its mechanisms of action. The results revealed that CGZ (10-50 $\mu \mathrm{mol} / \mathrm{l})$ inhibited the growth of leukemia NB4 cells and caused apoptosis in a time- and dose-dependent manner. Apoptosis was observed clearly by flow cytometry (FCM) and DNA fragmentation analysis. After treatment by CGZ for $48 \mathrm{~h}$, the percentage of disruption of mitochondrial membrane potential $(\Delta \psi \mathrm{m})$ was increased in a dose-dependent manner. Western blotting demonstrated the cleavage of caspase-3 zymogen protein and a time-dependent cleavage of poly (ADP-ribose) polymerase (PARP). The results also demonstrated that PPAR- $\gamma$ expression was increased concomitantly when apoptosis occurred, and that CGZ-induced apoptosis was inhibited by the PPAR- $\gamma$ antagonist GW9662, suggesting a PPAR- $\gamma$ dependent signaling pathway in CZG-induced cell death. Moreover, CGZ treatment remarkably downregulated the expression of the X-linked inhibitor of apoptosis protein (XIAP), which was inhibited by GW9662. Of note, a small-molecule XIAP antagonist (1396-12)
\end{abstract}

Correspondence to: Dr Jia-Jun Liu, Department of Hematology, The Third Affiliated Hospital of Sun Yat-sen University, Guangzhou, 510630, P.R. China

E-mail: jiajunliu2002@yahoo.com.cn

Dr Xiang-Yuan Wu, Department of Oncology, The Third Hospital of Sun Yat-Sen University, Guangzhou, 510630 P.R. China

E-mail: gz_med@126.com

${ }^{*}$ Contributed equally

Key words: peroxisome proliferator-activated receptor- $\gamma, \mathrm{X}$-linked inhibitor of apoptosis protein, acute promyelocytic leukemia, apoptosis mimicked the effect of CGZ-induced apoptosis via activation of caspase-3, 7 and 9. The apoptosis-inducing effects by CGZ on fresh APL cells were also found to be remarkable by using FCM and Wright's staining observation. Taken together, our results suggest that downregulation of XIAP and activation of capase-3 play an important role in mediating the PPAR- $\gamma$ dependent cell death induced by CGZ in APL cells. These data provide a novel insight into potential therapeutic strategies for treatment of leukemia.

\section{Introduction}

Peroxisome proliferator-activated receptor (PPAR) plays an important regulatory role in lipid and glucose metabolism, adipocyte differentiation, and energy homeostasis. PPAR- $\gamma$ is one of the best characterized nuclear hormone receptors (NHRs) in the superfamily of ligand-activated transcriptional factors (1). A large number of studies demonstrated that PPAR- $\gamma$ is expressed in a variety of types of cancer cells and has crucial roles in suppressing cancer cell growth (2-4). Previous studies show that PPAR- $\gamma$ expression is detected in a large number of hematological malignant cells such as myeloid and lymphoid leukemia cells (5-7). PPAR- $\gamma$ is activated not only by a naturally occurring arachidonic acid metabolite 15-deoxy- $\Delta$ (12,14)-prostaglandin J2 (15d-PGJ2), but also by synthetic ligands such as those belonging to the antidiabetic thiazolidinedione (TZD) class of compounds $(8,9)$. Recent studies show that activation of PPAR $-\gamma$ by either TZDs or $15 \mathrm{~d}-\mathrm{PGJ} 2$ leads to inhibition of cell growth and apoptosis in a large variety of cancer cells $(10,11)$.

Apoptosis plays an important role in prevention of leukemia development, and impaired apoptosis is now recognized as a key step in the pathogenisis of leukemia (12). Many studies show that defects in apoptosis signaling contribute to cancer cell drug resistance, and activation of apoptosis pathways is a key mechanism by which cytotoxic drugs kill cancer cells (13-15). Thus, induction of apoptosis is now considered as an important method of assessment for the clinical effectiveness of many anti-cancer drugs $(16,17)$. 
Acute myeloid leukemia (AML) is a group of several different diseases, the treatment and outcome of which depend on several factors, including leukemia karyotype, patient age, and comorbid conditions. Despite advances in understanding the molecular biology of AML, its treatment remains challenging. Standard regimens using cytarabine and anthracyclines for induction followed by some form of post-remission therapy produce response rates of $60-70 \%$, with $<20 \%$ of all patients achieving long-term disease-free survival $(18,19)$. Acute promyelocytic leukemia (APL) is a rare disease accounting for $\sim 10 \%$ of AML. This kind of leukemia is associated with a high risk of early mortality before the onset of therapy or in the early treatment phase resulting from severe coagulopathy, frequently inducing fatal cerebral hemorrhage, and the early mortality rate is $\sim 10 \%$ (20). Therefore, to find new antileukemia drugs and effective therapies for the clinical treatment of myeloid leukemia are common goals.

Though the PPAR- $\gamma$ ligand was proved to be very effective in treating a variety of caner cells, many of its anti-tumor mechanisms have not been demonstrated. Currently there is no detailed laboratory evidence showing the mechanisms of Ciglitazone (CGZ) on APL cells. In order to clarify some of its anti-leukemia mechanisms, we investigated the apoptotic effects of various concentrations of CGZ (10-50 $\mu \mathrm{mol} / \mathrm{l})$ on NB4 (APL cell line) and fresh APL cells in vitro.

\section{Material and methods}

Chemicals and reagents. CGZ, a kind of synthetic PPAR- $\gamma$ ligand, was purchased from Cayman Chemical Company (USA), dissolved in DMSO, and stored at $-20^{\circ} \mathrm{C}$. Antibodies against caspase-3, poly(ADP-ribose) polymerase (PARP), survivin, XIAP and $B$-actin were purchased from Santa Cruz Biotechnology (Germany). Caspase-3 Colorimetric assay kits and caspase inhibitor (z-DEVD-FMK) were purchased from R\&D Systems (Minneapolis, MN, USA). PCR primers (Shanghai Shenggong Company, Shanghai, China) were as follows: PPAR- $\gamma$ mRNA (474bp), sense primer, 5'-TCTCTCC GTAATGGAAGACC-3'; anti-sense primer, 5'-GCATTATG AGACATCCCCAC-3'; ß-actin mRNA (243 bp), sense primer, 5'-CTTCTACAATGAGCTGCGTG-3'; anti-sense primer, 5'-TCATGAGGTAG TCAGTCAGG-3'.

Cell culture. Human APL cell line NB4 cells (purchased from Shanghai Rui-jin Hospital) and fresh cells (obtained from newly diagnosed APL patients after obtaining informed consent) were cultured in RPMI-1640 medium supplemented with $10 \%$ heat-inactivated calf serum, and $100 \mathrm{U} / \mathrm{ml}$ penicillin in a humidified $5 \%$ incubator at $37^{\circ} \mathrm{C}$. Cells were passaged twice weekly and routinely examined for mycoplasma contamination.

Cell growth inhibitory rate. NB4 Cell growth inhibitory rate was assayed using the microculture tetrazolium method. Briefly, $2 \times 10^{5}$ cells/well were dispensed within 96-well culture plates in 100-ml volumes. Then different concentrations of CGZ (10, $20,30,40$ and $50 \mu \mathrm{mol} / \mathrm{l}$ ) were put in different wells (after many trials we found the above concentrations inhibit cell growth). Each of the concentrations above was regarded as an individual treated groups while the control group contained no CGZ. Each treated or control group contained 6 parallel wells. After culture plates were incubated for 0, 24, 48 and $72 \mathrm{~h}, 20 \mu \mathrm{l}$ of MTT working solution was added and then incubated continuously for $4 \mathrm{~h}$. All culture medium supernatant was removed from each well after centrifugation and replaced with $100 \mu 1$ of DMSO. Following thorough solublization, the absorbance (A value) of each well was measured using a microculture plate reader at $570 \mathrm{~nm}$. Cell inhibitory rate was calculated according to the formula, inhibitory rate $=100 \mathrm{x}$ (A value of control group-A value of treated group)/A value of control group.

NB4 cell viability assay. Cell viability was assessed by Trypan Blue dye exclusion method. Briefly, cells treated with different concentrations of CGZ were collected and Trypan Blue solution was added to the cells in equal volume. Then, cells were counted using hemacytometer after 15-20 min of incubation at room temperature and the ratio of viable cells to the total number of cells was calculated and recorded.

Flow cytometry analysis for cell apoptosis. After cells were treated with different concentrations of CGZ for $48 \mathrm{~h}$, apoptosis was assayed by annexin $\mathrm{V}$ and propidium iodide (PI) staining and analyzed by flow cytometry (FACScan, Becton Dickinson; Mountain View, CA) according to the manufacturer's protocol. The experiments were repeated three times and the results were presented as mean $\pm \mathrm{SD}$.

DNA fragmentation assay. Apoptosis was confirmed by detection of fragmentation of chromosomal DNA with the classic DNA ladder method. Briefly, after treatment by different concentrations of CGZ for $48 \mathrm{~h}, 1 \times 10^{6}$ cells were immersed in cytolysis buffer and incubated for $3 \mathrm{~h}$ at $50^{\circ} \mathrm{C}$. DNA was extracted with phenol-chloroform, precipitated in $1 / 10$ volume of $\mathrm{NaAc} 2 \mathrm{~mol} / \mathrm{l}$ and 2 volumes of ethanol at $-20^{\circ} \mathrm{C}$ overnight, recovered by centrifugation at $1,000 \mathrm{x}$ g for 30 min at $4^{\circ} \mathrm{C}$, and then resuspended in TE buffer. RNase A was then added at a concentration of $200 \mathrm{mg} / \mathrm{l}$, then the treated extract was incubated at $37^{\circ} \mathrm{C}$ for $30 \mathrm{~min}$ and electrophoresed on a $1.2 \%$ agarose gel.

Western blot analysis. For Western blotting, cells were harvested and disrupted in lysis buffer (1\% Triton X-100, 1 mM EGTA, 1 mM EDTA, 10 mM Tris-HCl, pH 7.4). Cell debris was removed by centrifugation at $10,000 \mathrm{x} g$ for $10 \mathrm{~min}$ at $4{ }^{\circ} \mathrm{C}$. The resulting supernatants were resolved on a $10 \%$ SDS-PAGE under denatured reducing conditions and transferred to nitrocellulose membranes. The membranes were blocked with 5\% non-fat dried milk at room temperature for $30 \mathrm{~min}$ and incubated with different primary antibodies. The membranes were washed and incubated with horseradish peroxidase-conjugated secondary antibodies. As an internal control, $\beta$-actin was also detected. The immunoreactive proteins were detected using an ECL Western blotting detection system.

Analysis of the mitochondrial membrane potential. The mitochondrial membrane potential $(\Delta \psi \mathrm{m})$ was measured by FCM using the intramitochondrial dye JC-1 (Alexis Biochemical Co., Germany) after NB4 cells treated with different concentrations of CGZ for $48 \mathrm{~h}$. The detection procedure was performed according to the manufacturer's 

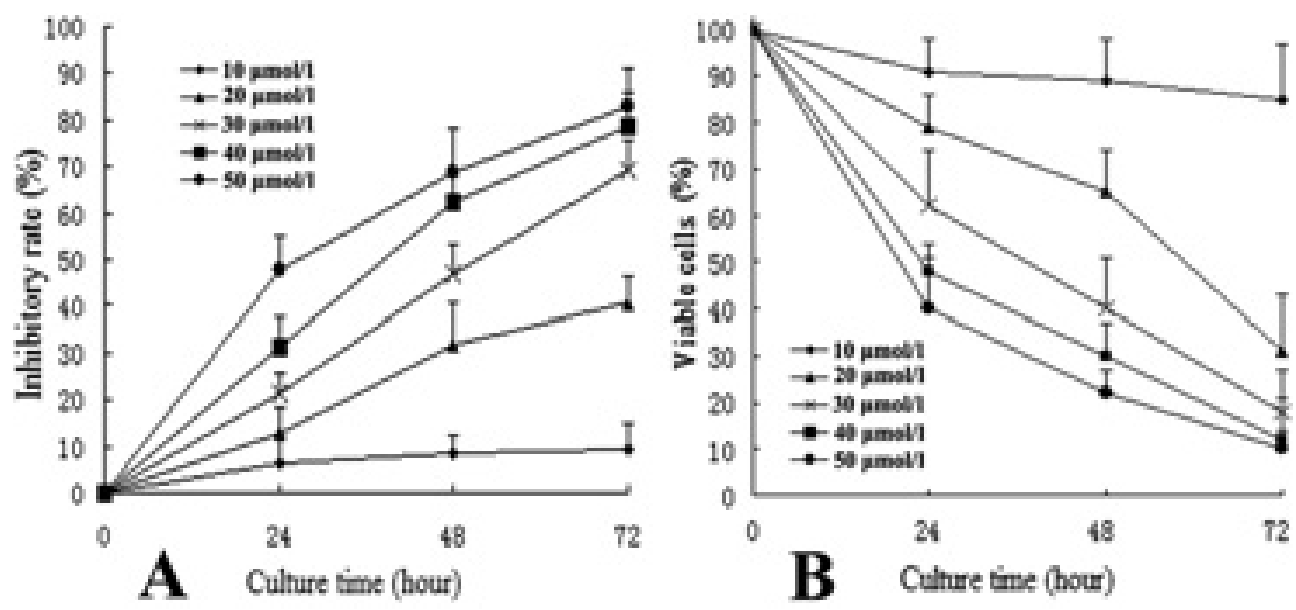

Figure 1. Cell growth inhibition caused by CGZ. (A) Cell growth inhibitory rate. After NB4 cells were treated with different concentrations of CGZ, MTT assay was used to detect cell growth inhibitory rate as described in Methods and materials. (B) Cell viability. After NB4 cells were treated with different concentrations of CGZ, Trypan Blue dye exclusion method was used to detect cell viability. The ratio of viable cells to the total number of cells was significantly reduced especially when the cells were treated with 40 and $50 \mu \mathrm{mol} / \mathrm{l} \mathrm{CGZ}$ for $72 \mathrm{~h}$.

instructions. Data were converted to dot plots using Cell Quest software (Becton Dickison, Germany).

$R T-P C R$. RT-PCR was used to detect the expression of PPAR- $\gamma$ after NB4 cells were treated with $40 \mu \mathrm{mol} / 1 \mathrm{CGZ}$ for 12,24 , 48 and $72 \mathrm{~h}$. The total RNA was extracted by using Trizol reagent. First-stranded cDNA was synthesized using $5 \mu \mathrm{g}$ total RNA by RT-PCR kit. The PCR reactions for PPAR- $\gamma$ and $\beta$-actin cDNAs were performed with 30 amplification cycles and the reaction conditions were, denaturation at $94^{\circ} \mathrm{C}$ for $1 \mathrm{~min}$, annealing at $53^{\circ} \mathrm{C}$ for $2 \mathrm{~min}$, and extension at $72^{\circ} \mathrm{C}$ for $3 \mathrm{~min}$. All of the above PCR reactions were incubated in an automatic heat-block (Model PJ 2000 DNA Thermal Cycler). The PCR products were then run on $1.5 \%$ agarose gel and visualized by ethidium bromide staining.

Immunocytochemistry. PPAR- $\gamma$ protein was also detected by immunocytochemistry. Briefly, After NB4 cells were treated with $40 \mu \mathrm{mol} / 1 \mathrm{CGZ}$ for $12,24,48$ and $72 \mathrm{~h}$, cells were harvested and evaluated by immunostaining. The primary antibody was a rabbit polyclonal anti-PPAR- $\gamma(1: 1,000$; Santa Cruz, CA), and the secondary antibody an Alexa-conjugated goat anti-rabbit IgG (Molecular Probes, Eugene).

Caspase activity assay. Activity of caspases was determined by Caspase Colorimetric assay kit, according to the manufacturer's protocol. Briefly, cells were washed with ice-cold PBS and lysed in a lysis buffer. Cell lysates were tested for protease activity using a caspase-specific peptide, conjugated to the color reporter molecule p-nitroanaline. The chromophore p-nitroanaline, cleaved by caspases, was quantitated with a spectrophotometer at a wavelength of $405 \mathrm{~nm}$. The caspase enzymatic activities in cell lysate are directly proportional to the color reaction.

Growth inhibition of CGZ in fresh APL cells. To show the effects of CGZ on fresh APL cells, MTT assay was also used to determine the cell growth inhibitory rate caused by 10,20 , 30, 40 and $50 \mu \mathrm{mol} / 1 \mathrm{CGZ}$ as described above.
CGZ induced apoptosis in fresh APL cells. CGZ-induced apoptosis in fresh APL cells was also detected by FCM. Briefly, after the cells were treated with different concentrations of CGZ for $48 \mathrm{~h}$, cells were harvested and stained with Annexin-V-FITC, then apoptosis was analyzed by FCM.

Apoptotic morphology of fresh APL cells observed by Wright's staining. After the cells were treated by different concentrations of CGZ for $48 \mathrm{~h}$, cells were harvested and observed by Wright's staining. The morphological variations, such as apoptosis as well as maturation and differentiation, were observed.

Statistical analysis. All experiments were performed in triplicate and the results were expressed as mean \pm SD. Statistical analysis was performed with a Student's t-test using SAS 6.12 software. Statistical significance was accepted at the level of $\mathrm{P}<0.05$.

\section{Results}

NB4 cell growth inhibition caused by CGZ. CGZ (10 $\mu \mathrm{mol} / \mathrm{l})$ had a smaller inhibitory rate on NB4 cells, but it inhibited the growth of NB4 cells significantly at a higher concentration, especially when the concentration was $>30 \mu \mathrm{mol} / 1$. The inhibitory rate caused by $50 \mu \mathrm{mol} / \mathrm{l} \mathrm{CGZ} \mathrm{was} \mathrm{much} \mathrm{higher}$ $(>90 \%)$ than that of lower concentrations of CGZ $(p<0.01)$ (Fig. 1A). The number of viable cells were also observed by Trypan Blue dye exclusion method. As shown in Fig. 1B, the ratio of viable cells to the total number of cells was significantly reduced in a time- and dose-dependent manner.

Apoptosis inducing effects by CGZ on leukemia NB4 cells. We first detected the apoptosis inducing effects by flow cytometry after treatment by different concentrations of CGZ for $48 \mathrm{~h}$. As shown in Fig. 2, CGZ induced apoptosis on leukemia NB4 cells in a dose-dependent manner. The apoptosis-inducing effects were confirmed by DNA fragmentation analysis. As shown in Fig. 3, incubation of leukemia NB4 cells with different concentrations of CGZ for 48 h elicited characteristic 'ladders' of DNA fragments. 

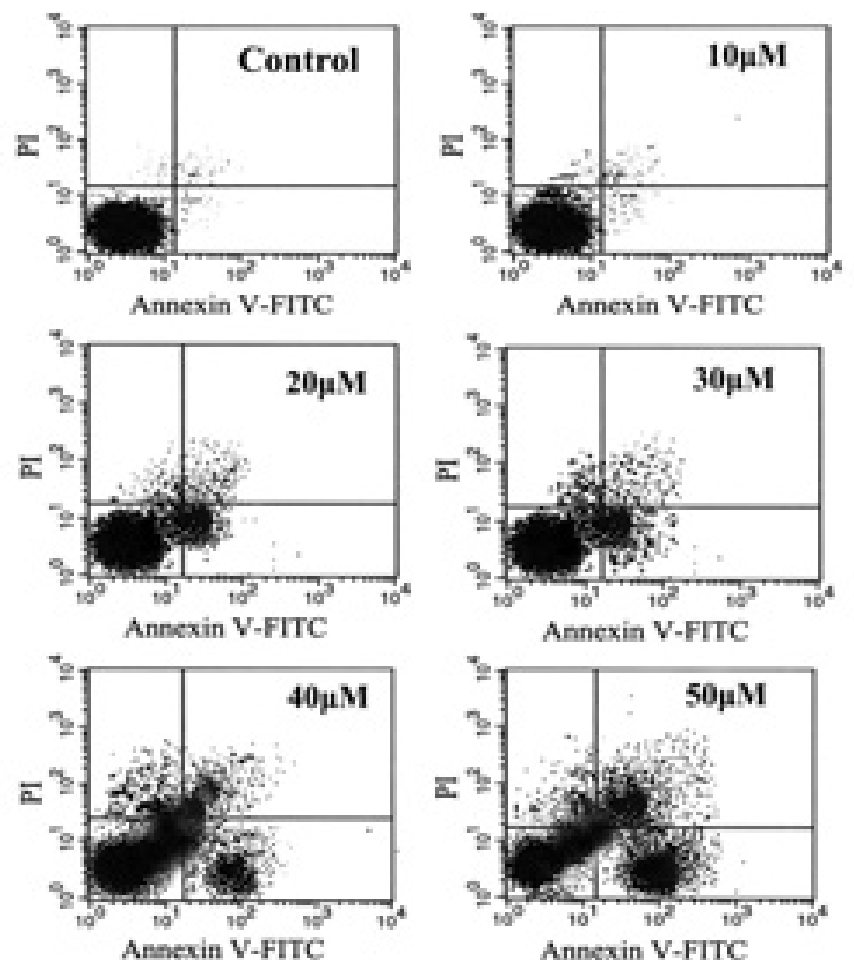

Figure 2. Cell apoptosis caused by CGZ. After NB4 cells were treated with different concentrations of CGZ for $48 \mathrm{~h}$, cells were harvested and stained by annexin $\mathrm{V}$ and propidium iodide (PI) staining. Then apoptosis was analyzed by FCM. The percentage of apoptotic cells gradually increased in a dose-dependent manner. After treatment by $0-50 \mu \mathrm{mol} / \mathrm{l} \mathrm{CGZ} \mathrm{for} 48 \mathrm{~h}$, the apoptotic cells were, $2.1 \%$ (Control, $0 \mu \mathrm{mol} / \mathrm{l}) ; 8.6 \%$ (10 $\mu \mathrm{mol} / 1) ; 21.8 \%$ (20 $\mu \mathrm{mol} / 1) ; 35.9 .6 \%$ (30 $\mu \mathrm{mol} / 1) ; 48.5 \%(40 \mu \mathrm{mol} / 1)$ and $52.6 \%(50 \mu \mathrm{mol} / 1)$.

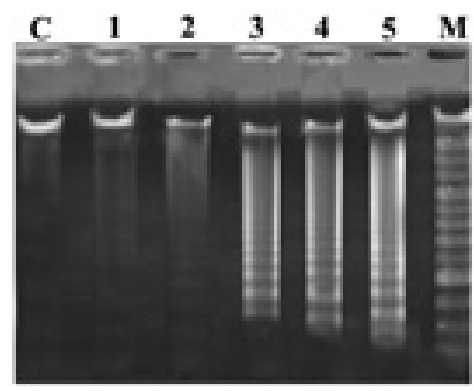

Figure 3. DNA fragmentation analysis. Apoptosis was confirmed by detection of fragmentation of chromosomal DNA with the classic DNA ladder method. DNA ladder was observed clearly after the cells were treated for $48 \mathrm{~h}$. Lanes 1, 2, 3, 4 and 5 were, 10, 20, 30, 40 and $50 \mu \mathrm{mol} / 1 \mathrm{CGZ}$. C, control (0 $\mu \mathrm{mol} / \mathrm{l} \mathrm{CGZ);} \mathrm{M,} 100$ bp DNA marker.

Disruption of $\Delta y m$. To clarify the apoptotic mechanisms caused by CGZ, the mitochondrial membrane potential was examined after treatment with different concentrations of CGZ for $48 \mathrm{~h}$. As shown in Fig. 4, the cells exhibited a significant alteration in $\Delta \psi \mathrm{m}$. The percentage of disruption of $\Delta \psi \mathrm{m}$ was increased in a dose-dependent manner (Fig. 4). This suggests that CGZ-induced apoptosis involves the mitochondrial signaling pathway.

Activation of caspase-3. To understand the activation of the caspase cascade during CGZ-induced apoptosis in leukemia NB4 cells, we investigated the variation of caspase- 3 after the cells were treated with $40 \mu \mathrm{mol} / \mathrm{l} \mathrm{CGZ}$ for $12,24,48$ or $72 \mathrm{~h}$.

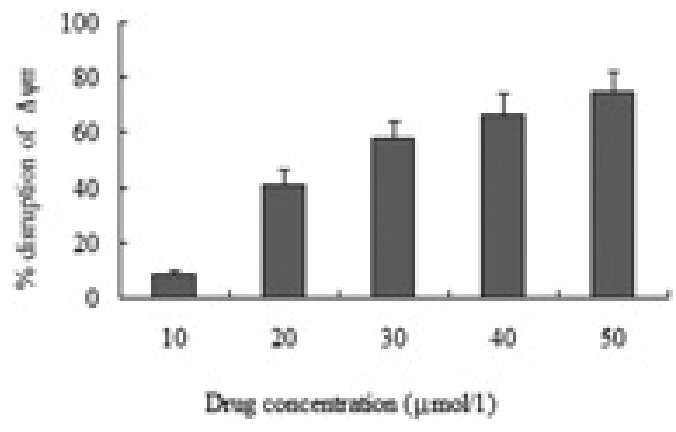

Figure 4. Disruption of mitochondrial membrane potential $(\Delta \psi \mathrm{m})$. The variation of $\Delta \psi \mathrm{m}$ was analyzed as described in the Materials and methods after treatment by CGZ for $48 \mathrm{~h}$. The cells exhibited significant alterations in $\Delta \psi \mathrm{m}$, and the percentage of disruption of $\Delta \psi \mathrm{m}$ gradually increased in a dose-dependent manner.

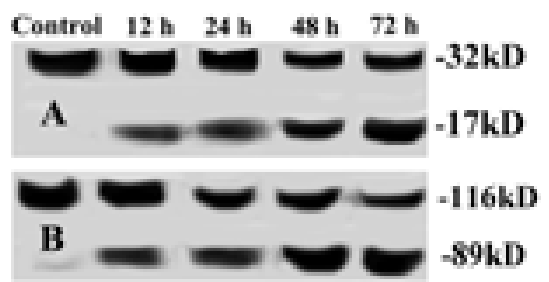

Figure 5. Western blot analysis of caspase-3. After the cells were treated by $40 \mu \mathrm{mol} / \mathrm{l} \mathrm{CGZ}$ for $12,24,48$ and $72 \mathrm{~h}$, expression of caspase- 3 and PARP was analyzed by Western blotting. Caspase- 3 was activated by the loss of caspase- 3 proenzyme $(32 \mathrm{kD})$ and the appearance of its $17-\mathrm{kD}$ subunit (A). CGZ treatment also caused a time-dependent cleavage of PARP, with the appearance of an $89-\mathrm{kD}$ fragment and disappearance of the intact 116-kD PARP (B).

As shown in Fig. 5A, treatment of the cells with $40 \mu \mathrm{mol} / \mathrm{l} \mathrm{CGZ}$ resulted in the cleavage of $32-\mathrm{kD}$ caspase- 3 zymogen protein and the appearance of its $17-\mathrm{kD}$ subunit. To confirm that CGZ induces the activation of caspase-3, the cleavage of poly (ADP-ribose) polymerase (PARP) was also examined by Western blotting. As shown in Fig. 5B, CGZ treatment caused the time-dependent proteolytic cleavage of PARP, with the appearance of an $89-\mathrm{kD}$ fragment and disappearance of the intact $116-k D$ PARP.

To estimate the contribution of caspase- 3 to CGZ-induced cell apoptosis, cells were pretreated with z-DEVD-FMK (20 $\mu \mathrm{mol} / \mathrm{l})$, a caspase-3-specific inhibitor, prior to Tan I treatment. The cells were first treated with z-DEVD-FMK for $1 \mathrm{~h}$, then incubated with $40 \mu \mathrm{mol} / 1 \mathrm{CGZ}$ for $12,24,48$ and $72 \mathrm{~h}$. As shown in Fig. 6A, $1 \mathrm{~h}$ pre-treatment with z-DEVDFMK blocked the activation of caspase-3-induced CGZ. Consistent with these results, CGZ-induced PARP cleavage was also inhibited by z-DEVD-FMK (Fig. 6B), indicating that Tan I-induced apoptosis was mediated via the activation of caspase-3.

Variation of PPAR- $\gamma$ expression caused by CGZ treatment. After treatment by $40 \mu \mathrm{mol} / 1 \mathrm{CGZ}$ for $12,24,48$ or $72 \mathrm{~h}$, RT-PCR and Western blotting were used to detect PPAR- $\gamma$ expression. As shown in Fig. 7A, expression of PPAR- $\gamma$ mRNA (474 bp) was gradually enhanced in a time-dependent manner. Consistent with these results, PPAR- $\gamma$ protein $(\sim 55 \mathrm{kD})$ expression was also increased, observed by Western blotting 


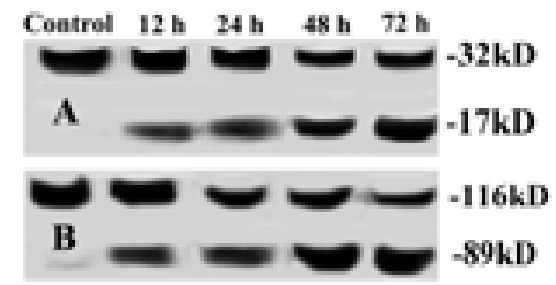

Figure 6. Caspase-3 inhibitor (z-DEVD-FMK) blocked activation of caspase-3. Pre-treatment with specific caspase inhibitor z-DEVD-FMK blocked the activation of caspase- 3 induced by CGZ treatment (A). CGZ-induced PARP cleavage was also inhibited by z-DEVD-FMK (B).

(Fig. 7B). Immunocytochemistry was also used to observe the variation of PPAR- $\gamma$ protein. As shown in Fig. 8, PPAR- $\gamma$ protein (green) was expressed in leukemia NB4 cells and localized predominantly in the cell nucleus, and only a less amount of PPAR- $\gamma$ protein was found in the cytoplasm. After treatment by $40 \mu \mathrm{mol} / \mathrm{l} \mathrm{CGZ}$ for $12,24,48$ or $72 \mathrm{~h}$, fluorescent intensity of PPAR- $\gamma$ protein was increased remarkably in a time-dependent manner.

CGZ-induced apoptosis was inhibited by PPAR- $\gamma$ antagonist GW9662. To investigate whether CGZ-induced apoptosis in NB4 cells is PPAR- $\gamma$ dependent, GW9662 (GW) was used to observe whether CGZ-induced apoptosis in leukemia NB4 cells is blocked by PPAR- $\gamma$ antagonist. Briefly, $2 \times 10^{6}$ cells were exposed to $40 \mu \mathrm{mol} / \mathrm{l} \mathrm{CGZ}$ for $48 \mathrm{~h}$ in the presence or absence of 2 and $5 \mu \mathrm{mol} / 1 \mathrm{GW}$. Then cells were harvested and apoptosis was observed by DNA fragmentation and FCM analysis. As shown in Fig. 9, characteristic 'ladders' of DNA fragments were not found after treatment by 2 or $5 \mu \mathrm{mol} / 1$

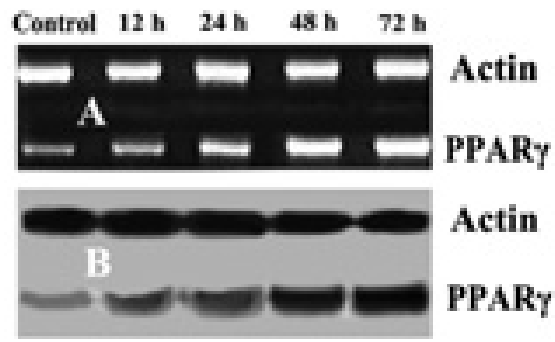

Figure 7. PPAR- $\gamma$ expression caused by CGZ treatment. After treatment by $40 \mu \mathrm{mol} / 1 \mathrm{CGZ}$ for different times, RT-PCR revealed that the expression of PPAR- $\gamma$ mRNA (474 bp) was gradually enhanced in a time-dependent manner (A). PPAR- $\gamma$ protein ( 55 kD) expression was also increased by Western blot analysis (B). B-actin was used as an internal control.

GW for 48 h. Consistent with these results, FCM detection revealed that apoptotic cells were decreased significantly after treatment by GW (Fig. 10). These results indicate that the PPAR- $\gamma$ signaling pathway is involved in CGZ-induced apoptosis in leukemia NB4 cells.

Downregulation of XIAP was involved in CGZ-induced apoptosis. XIAP and survivin belong to inhibitors of apoptosis proteins (IAP). Expression of XIAP and survivin were reported to be in most cancer cells and their increased expression is associated with poor prognosis (21). In order to clarify whether CGZ-induced apoptosis in leukemia NB4 cells is related to the changes of IAP, we detected the expression of XIAP and survivin after NB4 cells were treated by $40 \mu \mathrm{mol} / \mathrm{l}$ CGZ for 12, 24, 48 and $72 \mathrm{~h}$. As shown in Fig. 11A, the results revealed that the expression of XIAP was downregulated remarkably in a time-dependent manner, while the expression of survivin
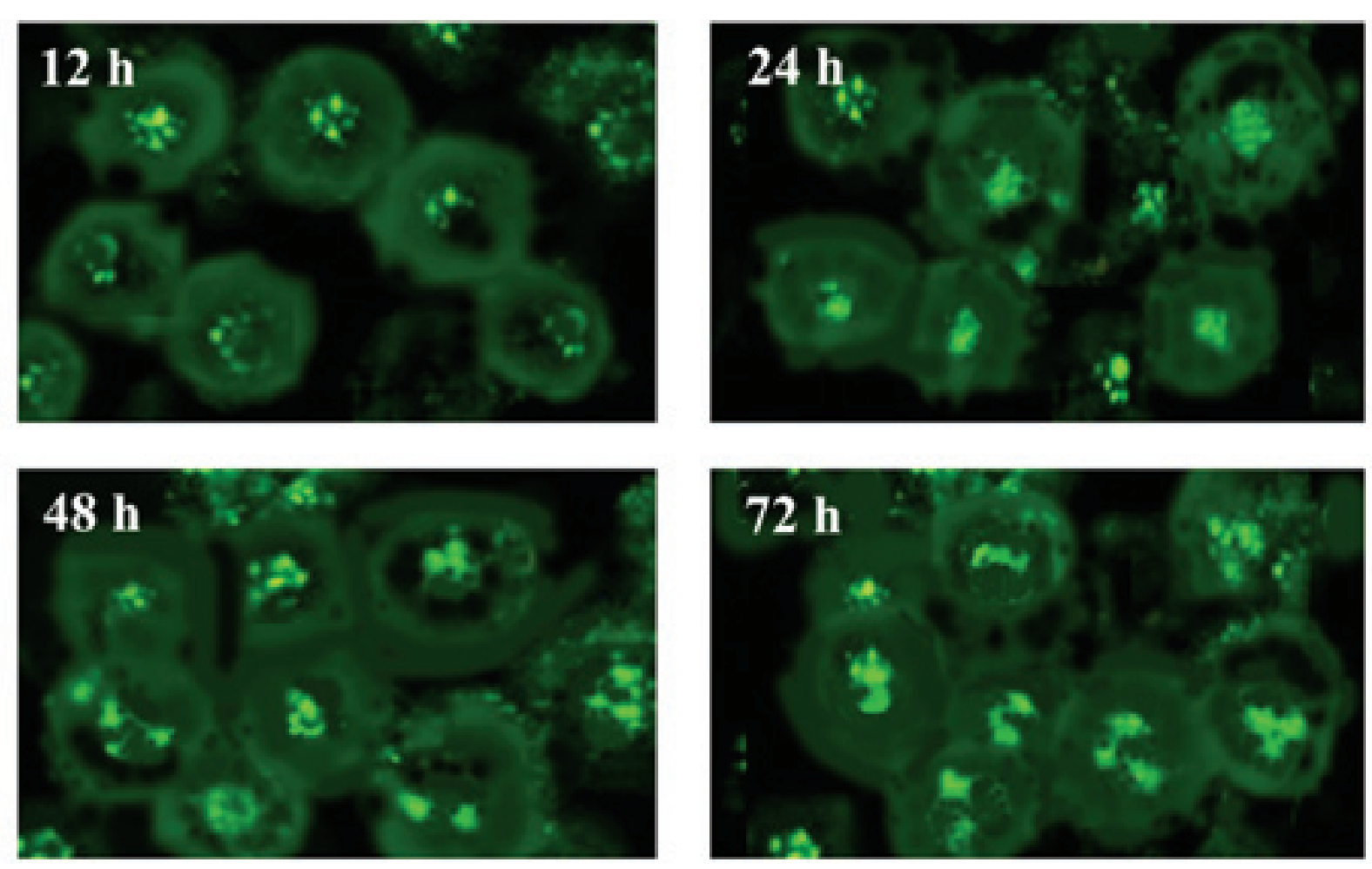

Figure 8. Cell immunostaining. Immunocytochemistry was used to observe PPAR- $\gamma$ protein. PPAR- $\gamma$ protein (green) was localized predominantly in the cell nucleus and increased remarkably in a time-dependent manner after treatment with $40 \mu \mathrm{mol} / \mathrm{l} \mathrm{CGZ}$. 


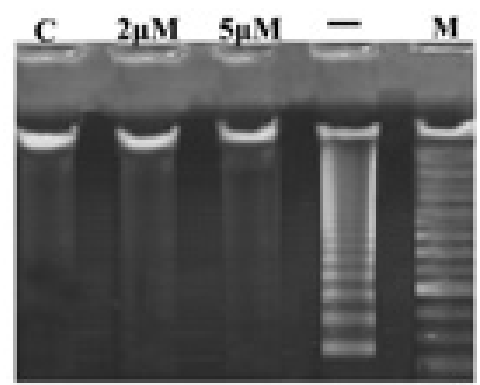

Figure 9. CGZ-induced DNA fragmentation was inhibited by GW9662. Characteristic 'ladders' of DNA fragments were inhibited by treatment of 2 or $5 \mu \mathrm{mol} / 1 \mathrm{GW} 9662$ for $48 \mathrm{~h}$.

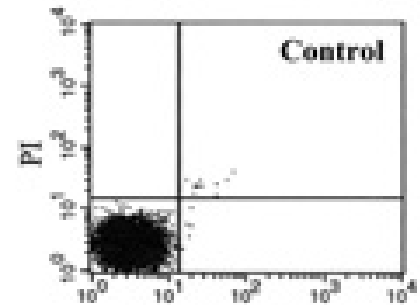

Annexin V-FITC

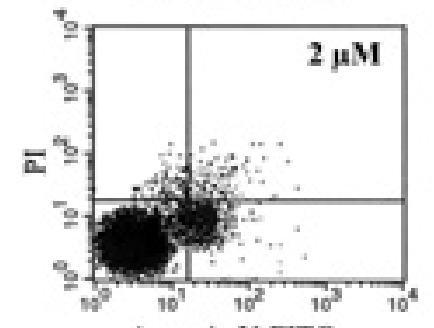

Annexin V-FITC

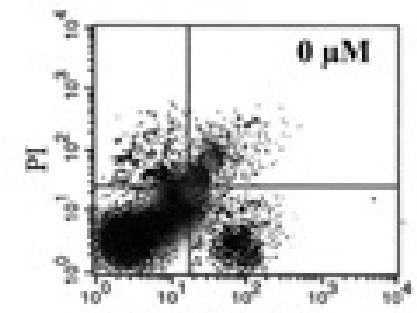

Annexin V-FITC

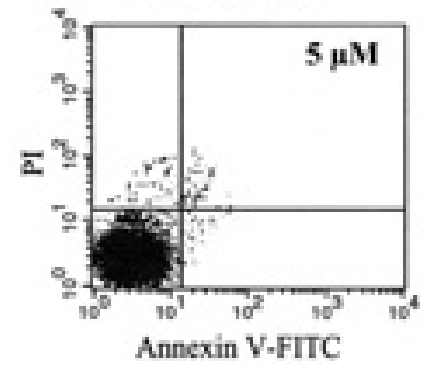

Figure 10. FCM analysis of GW9662 revealed apoptosis inhibition. FCM detection revealed that apoptotic cells were decreased significantly after treatment by GW for $48 \mathrm{~h}$, indicating that the PPAR- $\gamma$ signaling pathway was involved in CGZ-induced apoptosis in leukemia NB4 cells.

remained unchanged when apoptosis occurred. The results indicate that the change of XIAP expression was involved in CGZ-induced apoptosis in NB4 cells. To examine whether CGZ-induced downregulation of XIAP is PPAR- $\gamma$-dependent, we observed the expression of XIAP after cells were exposed to $40 \mu \mathrm{mol} / \mathrm{l} \mathrm{CGZ} \mathrm{for} 48 \mathrm{~h}$ in the presence of 2 or $5 \mu \mathrm{mol} / 1$ GW. As shown in Fig. 11B, Western blotting revealed that CGZ-induced downregulation of XIAP was inhibited by GW9662, suggesting that CGZ induced downregulation of XIAP through a PPAR- $\gamma$-dependent mechanism.

XIAP antagonist (1396-12) mimicks the effect of CGZinduced apoptosis. XIAP is one of the most potent inhibitors of the apoptosis cascade and suppresses apoptosis triggered by many apoptosis inducing factors (22). In order to verify if downregulation of XIAP is required for CGZ-induced apoptosis through activation of PPAR- $\gamma$, we observed the apoptosis inducing effects and detected the activity of caspase-3, 7 and 9 in NB4 cells caused by a small-molecule antagonist 1396-12 (kindly provided by Dr F. Wang, Division of Glial Disease and Therapeutics, Department of Neurosurgery, University of

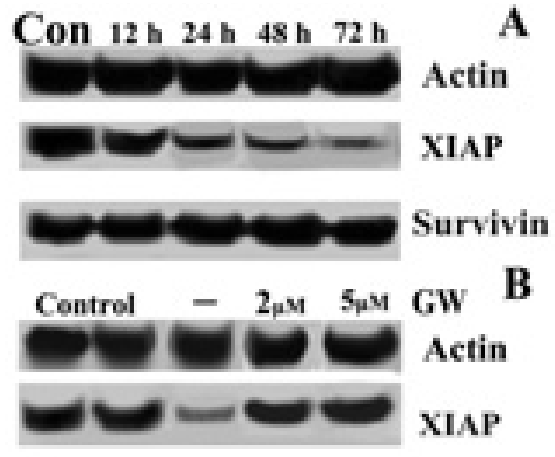

Figure 11. Expression of XIAP and survivin in CGZ-induced apoptosis. NB4 cells were treated with $40 \mu \mathrm{mol} / \mathrm{l} \mathrm{CGZ}$ for various times. Cytosol fraction was prepared and subjected to Western blotting. Representative results from three independent experiments are shown. (A) Variation of XIAP and survivin expression. Treatment by CGZ down-regulated the expression of XIAP, whereas the expression of survivin remained unchaged. (B) Effect of GW9662 on CGZ-induced downregulation of XIAP. Cells were treated with $40 \mu \mathrm{mol} / 1$ CGZ for $48 \mathrm{~h}$ in the presence of 2 or $5 \mu \mathrm{mol} / 1 \mathrm{GW} 9662$. The results revealed that CGZ-induced downregulation of XIAP was inhibited by GW9662.
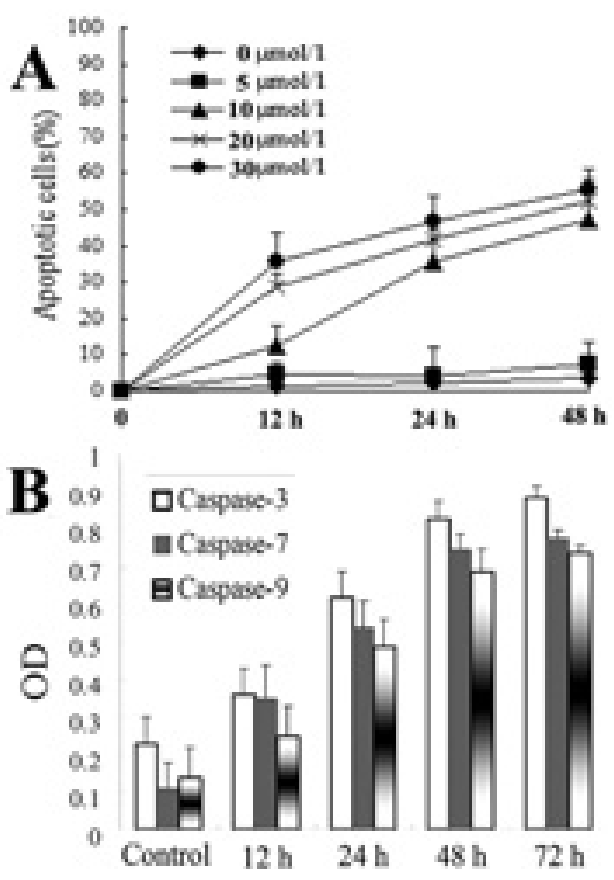

Figure 12. Apoptosis inducing effect by XIAP antagonist (1396-12). (A) XIAP antagonist (1396-12) induced apoptosis in NB4 cells. After NB4 cells were treated by 5, 10, 20 and $30 \mu \mathrm{mol} / 1$ XIAP 1396-12 for 12, 24 and $48 \mathrm{~h}$, the percentage of apoptotic cells was detected by FCM analysis. The results showed 1396-12 (over $10 \mu \mathrm{mol} / \mathrm{l}$ ) induced a time-dependent apoptosis in NB4 cells. (B) 1396-12 significantly increased the activity of caspase-3, -7 and -9 in a time-dependent manner, indicating that downregulation of XIAP plays an important role in mediating the PPAR- $\gamma$-dependent cell death induced by CGZ.

Rochester, Rochester, NY, USA), a phenylurea-based compound, to determine whether downregulation of XIAP mimics the effect of CGZ-induced apoptosis in leukemia NB4 cells. As shown in Fig. 12A, treatment by 10, 20 and $30 \mu \mathrm{mol} / \mathrm{l}$ 1396-12 induced time-dependent apoptosis after NB4 cells were treated for 12,24 and $48 \mathrm{~h}$. To estimate the contribution of caspases in XIAP antagonist-induced apoptosis on NB4 


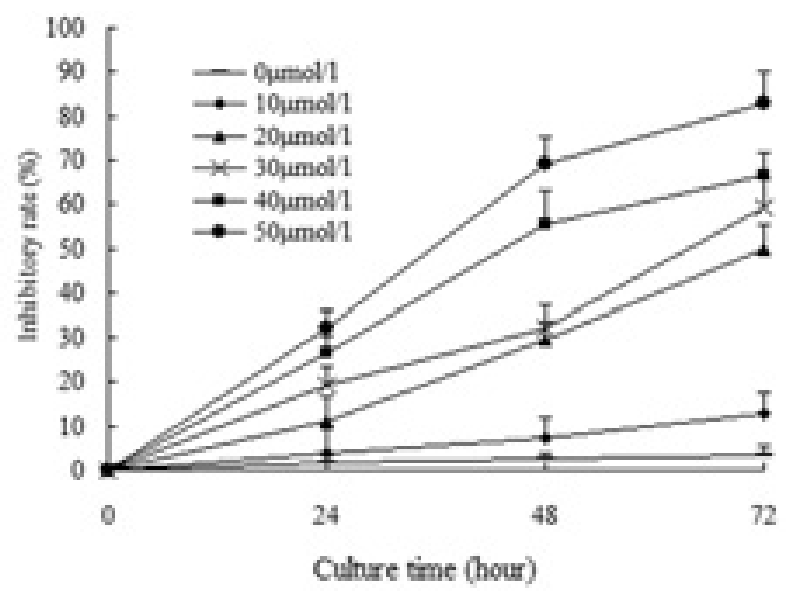

Figure 13. CGZ-induced cell growth inhibition on fresh APL cells. After fresh APL cells were treated by different concentrations of CGZ, MTT assay was used to detect the cell growth inhibitory rate. CGZ inhibited the growth of fresh APL cells in a time- and dose-dependent manner. Cell growth inhibitory rate was significantly increased especially when the cells were treated with $50 \mu \mathrm{mol} / \mathrm{l} \mathrm{CGZ}$ for $72 \mathrm{~h}$.

cells, we determined the activity of caspase- $-3,-7$ and -9 after cells were treated by $20 \mu \mathrm{mol} / 1$ 1396-12 for $12,24,48$ and $72 \mathrm{~h}$. As shown in Fig. 12B, 1396-12 significantly increased the activity of caspase-3, -7 and -9 in a time-dependent manner, indicating that downregulation of XIAP plays an important role in mediating the PPAR- $\gamma$-dependent cell death induced by CGZ.

Cell growth inhibition and apoptosis of fresh APL cells. CGZ inhibited the growth of fresh APL cells. As shown in Fig. 13, the cell growth inhibitory rate significantly increased especially when the cells were treated with 40-50 $\mu \mathrm{mol} / \mathrm{l} \mathrm{CGZ} \mathrm{for} 72 \mathrm{~h}$.

After the cells were treated with different concentrations of CGZ for $72 \mathrm{~h}$, cell apoptosis was detected by FCM. As shown in Fig. 14, the proportion of apoptotic cells gradually increased in a dose-dependent manner, 10, 20, 30, 40, and $50 \mu \mathrm{mol} / 1 \mathrm{CGZ}$-induced apoptotic cells were, $6.3 \pm 2.1 \%$

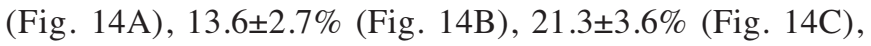
$39.6 \pm 6.7 \%$ (Fig. 14D) and $45.4 \pm 9.2 \%$ (Fig. 14E).

Fresh APL cell morphology observed by Wright's staining. After fresh APL cells were treated by different concentrations of CGZ for $72 \mathrm{~h}$, the cell morphology was observed by Wright's staining method. As shown in Fig. 15, morphology of cell apoptosis such as condensation of chromatin and nuclear fragmentations were also found clearly, and the number of dead cells gradually increased concurrently, whereas there was no cell differentiation or maturation in cell morphology during all the cultural period using Wright's staining observation.

\section{Discussion}

Synthetic PPAR- $\gamma$ ligands have demonstrated antileukemia effects by induction of cell apoptosis $(5,6)$. In this study, we found that CGZ inhibits cell growth and induces apoptosis in leukemia NB4 cells remarkably when the concentration of CGZ was $>20 \mu \mathrm{mol} / 1$. Apoptosis was observed clearly by flow cytometry (FCM) and DNA fragmentation analysis. After treatment by CGZ for $48 \mathrm{~h}$, the percentage of disruption of mitochondrial membrane potential $(\Delta \psi \mathrm{m})$ was increased in a dose-dependent manner. Western blotting demonstrated the cleavage of caspase-3 zymogen protein and a time-dependent cleavage of poly(ADP-ribose) polymerase (PARP). The results
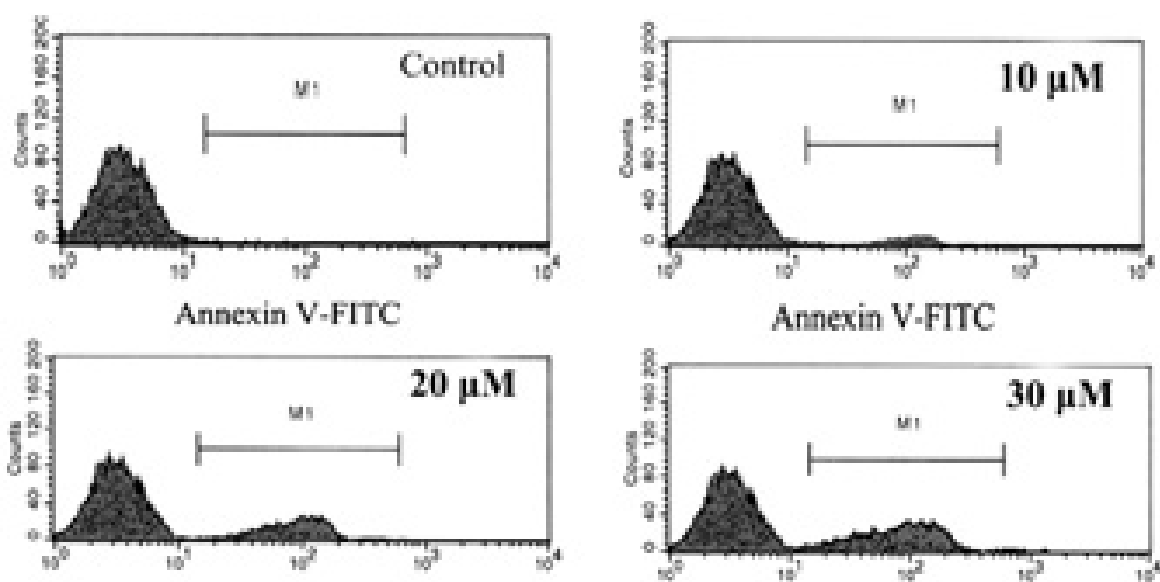

Annexin V-FITC

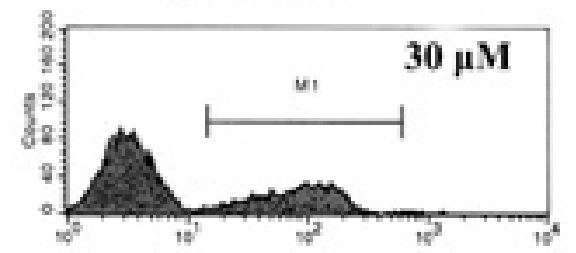

Annexin V-FITC.
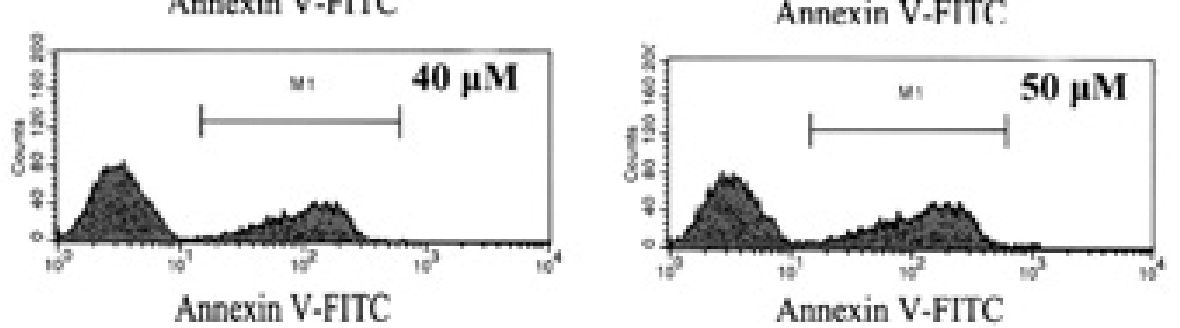

Annexin V-FITC

Figure 14. CGZ-induced apoptosis on fresh APL cells. After the cells were treated with different concentrations of CGZ for 72 h, cells were harvested and stained by Annexin-V, then apoptosis was detected by FCM. The proportion of apoptotic cells (M1) gradually increased in a dose-dependent manner, 10, 20,

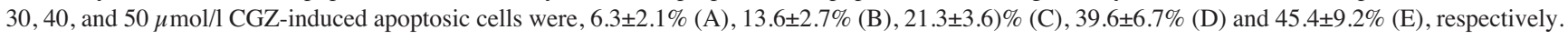



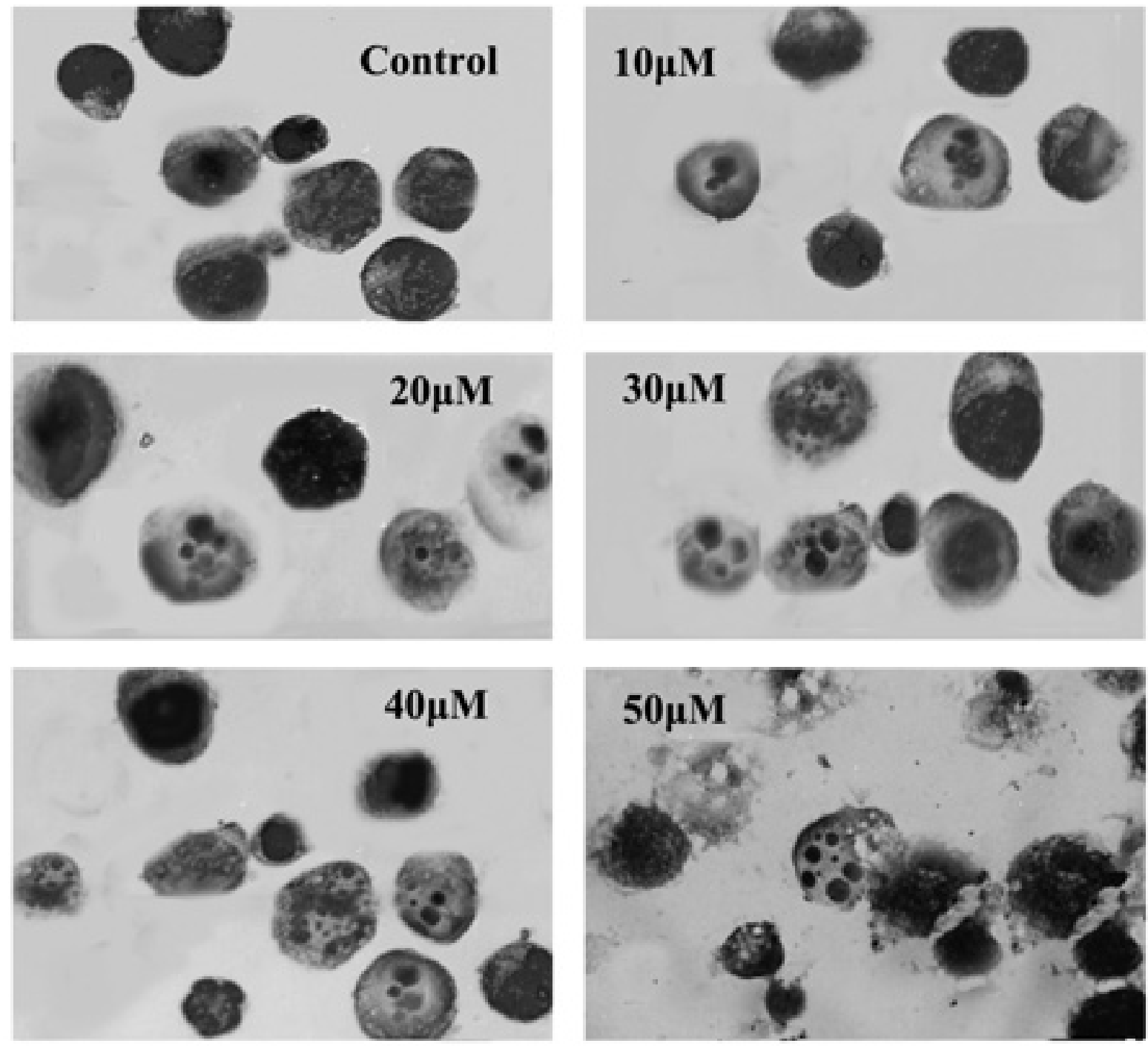

Figure 15. Apoptosis of fresh APL cells observed by Wright's staining. After fresh APL cells were treated with different concentrations of CGZ for 48 h, cells were harvested and observed by Wright's staining. Morphology of fresh APL cell apoptosis such as condensation of chromatin and nuclear fragmentations were also found clearly, whereas there was no cell differentiation or maturation in cell morphology after the cells were treated by different concentrations of CGZ.

also demonstrated that PPAR- $\gamma$ expression was increased concomitantly when apoptosis occurred, and that CGZ-induced apoptosis was inhibited by the PPAR- $\gamma$ antagonist GW9662, suggesting a PPAR- $\gamma$-dependent signaling pathway in CZGinduced cell death. Moreover, CGZ treatment remarkably downregulated the expression of XIAP, which was inhibited by GW9662. Of note, a small-molecule XIAP antagonist (1396-12) mimicked the effect of CGZ-induced apoptosis via activation of caspase-3, -7 and -9 . The apoptosis-inducing effects by CGZ on fresh APL cells were also found to be remarkable by using FCM and Wright's staining observation. Taken together, our results suggest that downregulation of XIAP and activation of caspase-3 plays an important role in mediating the PPAR- $\gamma$-dependent cell death induced by CGZ in APL cells. These results suggest that CGZ is an effective potential reagent for the treatment of leukemia. To our knowledge, this is the first report about the roles of CGZ on leukemia NB4 cells.

Dysregulation of apoptosis plays an important role in the development of leukemia. Targeted therapies that are designed to induce apoptosis in leukemic cells are currently the most promising antileukemia strategies (23). The elucidation of the molecular apoptotic machinery and its defects in leukemia lays the basis for developing new drugs that trigger apoptosis of leukemia cells $(23,24)$. Inhibitors of apoptosis proteins (IAPs) are a family of related proteins that suppress apoptosis induced by pro-apoptotic stimuli. Among IAP family members, XIAP and survivin have attracted considerable interest. The XIAP protein exerts its anti-apoptotic effect through inactivation of caspase-3, -7 , and -9 , and neutralizing the effect of XIAP may result in selective induction of apoptosis of cancer cells $(25,26)$. XIAP was found to be expressed in a large variety of acute myeloid leukemia cells and was currently used as a new anti-leukemia target $(23,27)$. Previous studies show that there is a considerable relationship between the level of XIAP expression and response to chemotherapy, and that leukemia patients with high XIAP levels have a shorter survival than that observed in patients with low XIAP levels $(27,28)$. XIAP inhibitors, such as antisense oligonucleotides and polyphenylurea-based small-molecule XIAP antagonists 
1396-12 were developed as new anti-cancer reagents $(29,30)$. Survivin is another anti-apoptotic factor and its expression was detected in the majority of leukemia cells. In order to clarify CGZ-induced apoptosis in NB4 cells, we detected the variation of XIAP and survivin expression. We observed here that the expression of XIAP was downregulated while survivin remained unchanged. These results suggest that CGZ induces apoptosis through downregulation of XIAP in NB4 cells. The effect of CGZ on XIAP expression was prevented by PPAR- $\gamma$ antagonist GW9662, suggesting that CGZ induced downregulation of XIAP through a PPAR- $\gamma$-dependent mechanism. To confirm the contribution of downregulation of XIAP in CGZ-induced apoptosis, we observed the effects of a smallmolecule XIAP antagonist (1396-12) on NB4 cells. The results revealed that 1396-12 mimicked the effect of CGZinduced apoptosis via activation of caspase-3, -7 and -9 .

Molecular mechanisms of apoptosis involve release of cytochrome $\mathrm{c}$ from mitochondria to the cytosol, thereby initiating a cascade of proteolytic events. Caspase-3 is one of the most important executioners which is capable of cleaving many important cellular substrates, and caspase- 3 mediated cell death plays an important role in pathogenesis and therapy of a variety of cancers $(31,32)$. Our results found that disruption of $\Delta \psi \mathrm{m}$ and activation of caspase-3 was highly correlated with CGZ-induced apoptosis in NB4 cells.

To investigate whether CGZ demonstrates apoptosis inducing effects on fresh APL cells, we further detected the growth inhibition effects and cell apoptotic rate as well as cell morphology by using FCM and Wright's staining observation. The results revealed that CGZ induces apoptosis on fresh APL cells, and there was no cell differentiation or maturation in cell morphology during the entire cultural period using Wright's staining observation. A recent study reported that pioglitazone, another synthetic PPAR- $\gamma$ ligand, stimulates myeloid differentiation in human leukemia NB4 cells (33). In the present studies no differentiation was found in APL cells, these different findings may be a result of by different PPAR- $\gamma$ ligands.

In summary, we conclude that downregulation of XIAP and activation of capase- 3 plays an important role in mediating the PPAR- $\gamma$-dependent cell death induced by CGZ in APL cells. These results suggest that CGZ is a potential effective reagent for the treatment of leukemia.

\section{Acknowledgements}

We thank the members of our laboratories for their insight and technical support. This work was supported by grants from the National Natural Foundation of China (No.30570786, No.30770782) and the Guangdong Natural Science Foundation of China (No.8151008901000128) as well as supported by the Program for New Century Excellent Talents in University (No. NCET-06-0721).

\section{References}

1. Zoete V, Grosdidier A and Michielin O: Peroxisome proliferatoractivated receptor structures: ligand specificity, molecular switch and interactions with regulators. Biochim Biophys Acta 1771: 915-925, 2007.

2. Krishnan A, Nair SA and Pillai MR: Biology of PPAR gamma in cancer: a critical review on existing lacunae. Curr Mol Med 7: 532-540, 2007.
3. Giaginis C, Margeli A and Theocharis S: Peroxisome proliferatoractivated receptor-gamma ligands as investigational modulators of angiogenesis. Expert Opin Investig Drugs 16: 1561-1572, 2007.

4. Ondrey F: Peroxisome proliferator-activated receptor gamma pathway targeting in carcinogenesis: implications for chemoprevention. Clin Cancer Res 15: 2-8, 2009.

5. Saiki M, Hatta Y, Yamazaki T, Itoh T, Enomoto Y, Takeuchi J, Sawada U, Aizawa S and Horie T: Pioglitazone inhibits the growth of human leukemia cell lines and primary leukemia cells while sparing normal hematopoietic stem cells. Int J Oncol 29: 437-443, 2006.

6. Wang T, Xu J, Yu X, Yang R and Han ZC: Peroxisome proliferatoractivated receptor $\gamma$ in malignant disease. Crit Rev Oncol Hematol 58: 1-14, 2006.

7. Ulivieri $\mathrm{C}$ and Baldari CT: The potential of peroxisome proliferatoractivated receptor gamma (PPAR gamma) ligands in the treatment of hematological malignancies. Mini Rev Med Chem 7: 877-887, 2007.

8. Coyle AT, O'Keeffe MB and Kinsella BT: 15-deoxy Delta12,14prostaglandin $\mathrm{J} 2$ suppresses transcription by promoter 3 of the human thromboxane A2 receptor gene through peroxisome proliferator-activated receptor gamma in human erythroleukemia cells. FEBS J 272: 4754-4773, 2005.

9. Richard CL and Blay J: Thiazolidinedione drugs down-regulate CXCR4 expression on human colorectal cancer cells in a peroxisome proliferator activated receptor $\gamma$-dependent manner. Int J Oncol 30: 1215-1222, 2007

10. Cekanova M, Yuan JS, Li X, Kim K and Baek SJ: Gene alterations by peroxisome proliferator-activated receptor $\gamma$ agonists in human colorectal cancer cells. Int J Oncol 32: 809-819, 2008.

11. Mrówka P, Glodkowska E, Nowis D, Legat M, Issat T, Makowski M, Szokalska A, Janowska S, Stoklosa T, Jakóbisiak M and Golab J: Ciglitazone, an agonist of peroxisome proliferatoractivated receptor $\gamma$, exerts potentiated cytostatic/ cytotoxic effects against tumor cells when combined with lovastatin. Int J Oncol 32: 249-255, 2008.

12. Schimmer AD: Induction of apoptosis in lymphoid and myeloid leukemia. Curr Oncol Rep 8: 430-436, 2006.

13. Barbera M, Kettunen MI, Caputo A, Hu DE, Gobbi S, Brindle KM and Carrara $\mathrm{M}$ : Immune-modulating and anti-vascular activities of two xanthenone acetic acid analogues: A comparative study to DMXAA. Int J Oncol 34: 273-279, 2009.

14. Xiao Y, Bi C, Fan Y, Cui C, Zhang X and Dou QP: L-glutamine Schiff base copper complex as a proteasome inhibitor and an apoptosis inducer in human cancer cells. Int J Oncol 33: 1073-1079, 2008.

15. Liu HB, Voso MT, Gumiero D, Duong J, McKendrick JJ and Dear AE: The anti-leukemic effect of a novel histone deacetylase inhibitor MCT-1 and 5-aza-cytidine involves augmentation of Nur77 and inhibition of MMP-9 expression. Int J Oncol 34: 573-579, 2009.

16. Song JH, Kim SH, Kim HJ, Hwang SY and Kim TS: Alleviation of the drug-resistant phenotype in idarubicin and cytosine arabinoside double-resistant acute myeloid leukemia cells by indomethacin. Int J Oncol 32: 931-936, 2008.

17. Conrad DM, Robichaud MR, Mader JS, Boudreau RT, Richardson AM, Giacomantonio CA and Hoskin DW: 2-Chloro2 -deoxyadenosine-induced apoptosis in T leukemia cells is mediated via a caspase-3-dependent mitochondrial feedback amplification loop. Int J Oncol 32: 1325-1333, 2008.

18. Jabbour EJ, Estey E and Kantarjian HM: Adult acute myeloid leukemia. Mayo Clin Proc 81: 247-260, 2006.

19. Thomas X: Chemotherapy of acute leukemia in adults. Expert Opin Pharmacother 10: 221-223, 2009.

20. Lengfelder E, Saussele S, Weisser A, Buchner T and Hehlmann R: Treatment concepts of acute promyelocytic leukemia. Crit Rev Oncol Hematol 56: 261-274, 2005.

21. Zangemeister-Wittke U and Simon HU: An IAP in action: the multiple roles of survivin in differentiation, immunity and malignancy. Cell Cycle 3: 1121-1123, 2004.

22. Wrzesien-Kus A, Smolewski P, Sobczak-Pluta A, Wierzbowska A and Robak T: The inhibitor of apoptosis protein family and its antagonists in acute leukemias. Apoptosis 9: 705-715, 2004.

23. Testa U and Riccioni R: Deregulation of apoptosis in acute myeloid leukemia. Haematologica 92: 81-94, 2007.

24. Del Poeta G, Bruno A, Del Principe MI, Venditti A, Maurillo L, Buccisano F, Stasi R, Neri B, Luciano F, Siniscalchi A, de Fabritiis P and Amadori S: Deregulation of the mitochondrial apoptotic machinery and development of molecular targeted drugs in acute myeloid leukemia. Curr Cancer Drug Targets 8: 207-222, 2008. 
25. Tian S, Mewani RR, Kumar D, Li B, Danner MT, Ahmad I, Rahman A, Notario V, Dritschilo A, Kasid UN and Gokhale PC: Interaction and stabilization of X-linked inhibitor of apoptosis by Raf-1 protein kinase. Int J Oncol 29: 861-867, 2006.

26. Andjilani M, Droz JP, Benahmed M and Tabone E: Downregulation of FAK and IAPs by laminin during cisplatin-induced apoptosis in testicular germ cell tumors. Int J Oncol 28: 535-542, 2006.

27. Schimmer AD: Apoptosis in leukemia: from molecular pathways to targeted therapies. Best Pract Res Clin Haematol 21: 5-11, 2008.

28. Tamm I, Richter S, Oltersdiorf D, Creutzig U, Harbott J, Scholz F, Karawajew L, Ludwig WD and Wuchter C: High expression levels of X-linked inhibitor of apoptosis protein and surviving correlate with poor overall survival in childhood de novo acute myeloid leukaemia. Clin Cancer Res 10: 3737-3744, 2004.

29. Schimmer AD, Dalili S, Batey RA and Riedl SJ: Targeting XIAP for the treatment of malignancy. Cell Death Differ 13: 179-188, 2006.
30. Cillessen SA, Reed JC, Welsh K, Pinilla C, Houghten R, Hooijberg E, Deurhof J, Castricum KC, Kortman P, Hess CJ, Ossenkoppele GJ, Meijer CJ and Oudejans JJ: Small-molecule XIAP antagonist restores caspase-9 mediated apoptosis in XIAP-positive diffuse large B-cell lymphoma cells. Blood 111: 369-375, 2008.

31. Gahr S, Ocker M, Ganslmayer M, Zopf S, Okamoto K, Hartl A, Leitner S, Hahn EG and Herold C: The combination of the histone-deacetylase inhibitor trichostatin A and gemcitabine induces inhibition of proliferation and increased apoptosis in pancreatic carcinoma cells. Int J Oncol 31: 567-576, 2007.

32. Philchenkov AA: Caspases as regulators of apoptosis and other cell functions. Biochemistry 68: 365-376, 2003.

33. Yasugi E, Horiuchi A, Uemura I, Okuma E, Nakatsu M, Saeki K, Kamisaka Y, Kagechika H, Yasuda K and Yuo A: Peroxisome proliferator-activated receptor $\gamma$ ligands stimulate myeloid differentiation and lipogenensis in human leukemia NB4 cells. Dev Growth Differ 48: 177-188, 2006. 